\title{
Atividade anti-Candida do extrato etanólico de Libidibia ferrea
}

\author{
ANTI-Candida activity of ethanolic extract of Libidibia ferrea \\ Actividad anti-Candida del extracto etanólico de Libidibia ferrea
}

\author{
Anna Luísa Barbosa Fernandes \\ ORCID: https://orcid.org/0000-0002-9746-6397 \\ Universidade Evangélica de Goiás, Brasil \\ E-mail: anninhabf@hotmail.com \\ Gil Guimaraes Barbosa Trivelli \\ ORCID: https://orcid.org/0000-0002-2248-9500 \\ Universidade Evangélica de Goiás, Brasil \\ E-mail: giltrivelli@hotmail.com \\ Júlia de Abreu Monteiro \\ ORCID: https://orcid.org/0000-0002-9374-4943 \\ Universidade Evangélica de Goiás, Brasil \\ E-mail:Juliabreu.med19@gmail.com \\ Marina Ramos Ribeiro \\ ORCID: https://orcid.org/0000-0002-8175-8061 \\ Universidade Evangélica de Goiás, Brasil \\ E-mail: marinaramosmed@gmail.com \\ Pedro Tomaz Esper \\ ORCID: https://orcid.org/0000-0002-7118-5001 \\ Universidade Evangélica de Goiás, Brasil \\ E-mail: petoes10@gmail.com \\ Humberto de Sousa Fontoura \\ ORCID: https://orcid.org/0000-0003-4858-1265 \\ Universidade Evangélica de Goiás, Brasil \\ E-mail: humbertofontoura@gmail.com \\ João Pedro Ribeiro Afonso \\ ORCID: https://orcid.org/0000-0002-1392-4910 \\ Universidade Evangélica de Goiás, Brasil \\ E-mail: joaopedro180599@gmail.com
}

\begin{abstract}
Resumo
Dentre as infecções fúngicas que acometem seres humanos, a candidíase apresenta muita relevância, tendo a Candida albicans como o agente etiológico mais comum. Porém, Candida parapsilosis e Candida tropicalis também têm emergido como causadoras de candidíase. Nativa da mata atlântica brasileira, a Libidibia ferrea é uma planta que tem sido estudada por sua capacidade de controle microbiológico. Portanto, o presente trabalho tem como objetivo avaliar a atividade antifúngica de $L$. ferrea sobre $C$. parapsilosis, $C$. albicans e $C$. tropicalis. A capacidade antifúngica dos extratos etanólicos de $L$. férrea foi analisada por meio do método de macrodiluição seriada, no qual identificou-se inibição na concentração máxima testada, a partir de $1,3 \%$ de rendimento do extrato. $O$ teste de sensibilidade em placas mostrou inibição do crescimento de $C$. albicans e $C$. tropicalis na maior concentração testada, enquanto a inibição de $C$. parapsilosis foi observada de maneira dose-dependente a partir de $0,5 \mathrm{mg} / \mathrm{mL}$ do extrato etanólico de $L$. ferrea. A capacidade antifúngica também foi avaliada por meio dos discos de difusão, dos quais não se observou inibição do crescimento de C. albicans, $C$. tropicalis e C. parapsilosis em nenhuma das concentrações realizadas. Além disso, foi realizado o teste de sinergismo entre o extrato e antifúngicos utilizados, observando ação sinérgica do extrato com fluconazol sobre as placas contendo C. parapsilosis, mas sem alterações sinérgicas ou antagônicas sob as demais espécies.
\end{abstract}

Palavras-chave: Candida ssp; Candidíase; Libidibia ferrea; Plantas medicinais.

\begin{abstract}
Candidiasis among the fungal infections that affect humans presents, with Candida albicans as the most common etiologic agent, however Candida parapsilosis and Candida tropicalis have emerged as causes of candidiasis episodes. Native to the Brazilian Atlantic Forest, a Libidibia ferrea, is a plant that has been studied for its microbiological control capacity. The present work aims to evaluate an antifungal activity of $L$. ferrea on $C$. parapsilosis, $C$. albicans and $C$. tropicalis. The evaluation of the antifungal capacity of the ethanolic extracts of $L$. ferrea was done using the method of serial macrodilution, and inhibition was identified in the maximum concentration tested, from $1.3 \%$ of the extract yield, according to the sensitivity test in plates. The antifungal capacity will be assessed using the broth dilution test and the diffusion disc method. In addition, an analysis of the synergism between
\end{abstract}


the extract and antifungals traditionally used will be carried out. Thus, it is expected that the ethanolic extract of $L$. ferrea will inhibit the growth of Candida ssp cells, thus generating a candidate for antifungal in association with conventional treatment or in monotherapy.

Keywords: Candida ssp; Candidiasis; Libidibia ferrea; Medicinal plants.

\section{Resumen}

Entre las infecciones fúngicas que afectan al ser humano, la candidiasis es muy relevante, siendo Candida albicans el agente etiológico más común. Sin embargo, Candida parapsilosis y Candida tropicalis también han surgido como causas de candidiasis. Originaria de la Mata Atlántica brasileña, Libidibia ferrea es una planta que ha sido estudiada por su capacidad de control microbiológico. Por tanto, el presente trabajo tiene como objetivo evaluar la actividad antifúngica de L. ferrea sobre C. parapsilosis, C. albicans y C. tropicalis. La capacidad antifúngica de los extractos etanólicos de L. ferrea se analizó mediante el método de macrodilución seriada, en el que se identificó la inhibición a la concentración máxima ensayada, a partir del 1,3\% del rendimiento del extracto. La prueba de sensibilidad en placas mostró inhibición del crecimiento de C. albicans y C. tropicalis a la concentración más alta probada, mientras que la inhibición de C. parapsilosis se observó de manera dosis-dependiente a partir de $0.5 \mathrm{mg} / \mathrm{mL}$ del extracto etanólico de L. planchar. La capacidad antifúngica también se evaluó mediante discos de difusión, los cuales no se observó que inhibieran el crecimiento de C. albicans, C. tropicalis y C. parapsilosis en ninguna de las concentraciones realizadas. Además, se realizó una prueba de sinergia entre el extracto y los agentes antifúngicos utilizados, observándose la acción sinérgica del extracto con fluconazol en las placas que contienen C. parapsilosis, pero sin cambios sinérgicos o antagonistas bajo las otras especies.

Palabras clave: Candida ssp; Candidiasis; Libidibia ferrea; Plantas medicinales.

\section{Introdução}

A candidíase é uma infeção fúngica oportunista causada por fungos do gênero Candida que pode se apresentar localizada ou sistêmica. Consiste em uma extensa variedade de síndromes clínicas, ocasionadas por, aproximadamente, 200 espécies diferentes de leveduras, que vivem normalmente nos mais diversos nichos corporais (Silva et al.,2019).

O gênero Candida tem como características espécies com aspecto morfológico leveduriforme, unicelulares, com parede fina e ovoides que, em grande parte das espécies, forma pseudo-hifas e hifas e são capazes de se reproduzir por meio de brotamento, seu aglomerado forma colônias, que possuem como características macroscópicas uma coloração branca a creme e uma superfície lisa ou rugosa (Lopes, 2018).

Várias espécies de Candida são caracterizadas como colonizadoras, desta forma, não são capazes de causar infecções a não ser que haja um desequilíbrio no sistema imune ou fatores externos, como os antimicrobianos, que podem alterar a microbiota normal (Campos et al.,2019). Portanto, a candidíase está extremamente relacionada com a resposta imunológica do paciente. A Candida albicans é a espécie que causa a maior quantidade de infecções superficiais e invasivas no ser humano e em diversas topografias anatômicas. Porém, outras espécies também estão associadas com essas infecções, bem como: Candida parapsilosis, Candida tropicalis, entre outras (Colombo et al, 2003). As manifestações clínicas também variam, podendo apresentar-se na forma mucocutânea, cutânea a e sistêmica (Lopes, 2018).

A candidíase atualmente tem se tornado uma doença cada vez mais prevalente. A cada 10 mil pacientes internados em hospitais com alto risco, cerca de 5 a 10 desenvolverão candidíase, sendo que de 35 a $50 \%$ dos pacientes podem chegar a óbito (Veronesi, 2015). Devido a sua grande diversidade de espécies aproximada de duzentas, os indivíduos estão consideravelmente suscetíveis a apresentar infecções fúngicas, com destaque a C. albicans (Colombo et al, 2003). Entretanto, diante do cenário atual, devido ao uso recorrente de terapia antifúngica profilática, empírica e preventiva essa espécie tem se tornado mais resistente abrindo espaço para outras espécies como a $C$. parapsilosis, e a C. tropicalis (Veronesi, 2015).

A farmacologia convencional para o tratamento de Candida spp. é a Anfotericina B, que é altamente eficaz para qualquer espécie desse grupo. Contudo, esse fármaco apresenta muitos efeitos colaterais no ser humano, como hepatotoxicidade, nefrotoxicidade e mesmo a flebite, no local de aplicação. Sendo assim, caso esses efeitos não consigam ser tolerados pelos pacientes, tem-se uma segunda opção de tratamento, que seria a Fluconazol, medicamento que apresenta menor 
toxidade, mas que também apresenta menor eficácia (Golan, 2009). Verificou-se uma acelerada seleção de indivíduos resistentes do gênero Candida a esse fármaco, devido à capacidade mutagênica da proteína p450, além disso, a interação medicamentosa do Fluconazol pode levar a grandes prejuízos. (Golan, 2009).

Diante do exposto, é possível perceber a necessidade crescente da busca por novos fármacos ou candidatos a fármacos no combate as infecções causadas por representantes do gênero Candida, que o façam de forma mais efetiva e menos tóxica. Vários estudos já vêm sendo realizados nesse sentido, com agentes naturais que demonstraram capacidade antifúngica, como Caryocar brasiliense, Aloe vera, Calendula officinalis, Curcuma longa, Zingiber officinale, Dioscorea bulbifera, Apis melífera, Arctiumlappa L., Stryphnodendron adstringens, Coville e Tabebuia avellanedae, e Lorentzex griseb. (Pereira et al., 2021) (Gazim et al., 2007).

Nesse interim, L. ferrea, popularmente conhecida como Jucá ou pau-ferro, pertence a uma das maiores famílias botânicas, as Fabaceae, adquiriu relevância. É uma planta bastante utilizada na medicina popular devido aos seus frutos que possuem ação contra diabetes e anemia, além da atividade anticancerígena (Cavalheiro et al., 2009). Possuemf lavonoides que conferem características anti-inflamatórias, os taninos com ação antisséptica e cicatrizante, e as cumarinas que são as principais responsáveis pela ação antibacteriana e antifúngica (Pereira et al., 2006).

Desta forma, diante do aumento de pacientes imunocomprometidos e o aparecimento de isolados resistentes e multirresistentes que tornam os fármacos cada vez mais ineficazes contra o agente causador, somado a alta toxicidade dos antifúngicos existentes e das diversas reações adversas que esses fármacos podem causar é de extrema importância à busca por novas terapias eficazes e menos tóxicas contra as diversas espécies do gênero Candida.

Desse modo, o objetivo deste estudo foi avaliar se o extrato etanólico de L. ferrea possui atividade antiproliferativa contra células de $C$. albicans, $C$. parapsilosis e $C$. tropicalis e, a partir do presente estudo, confirmou-se a atividade antiproliferativa contra células de C. albicans, C. parapsilosis e C. tropicalis.

\section{Metodologia}

\subsection{Tipo de estudo}

Foi realizado um estudo de caráter experimental, de abordagem indutiva, com procedimento comparativo estatístico e técnica de documentação direta em laboratório.

\subsection{Coleta do material vegetal}

A coleta das amostras de L. ferrea foi realizada na cidade de Tocantinópolis-TO/Brasil; coordenadas geográficas latitude $06^{\circ} 19^{\prime} 46^{\prime \prime}$ sul e a uma longitude $47^{\circ} 24^{\prime} 59^{\prime \prime}$ oeste. As amostras foram identificadas e reconhecidas pelo professor Carlos Melo, botânico e, posteriormente, armazenadas no Laboratório de Microbiologia da Universidade Evangélica de Goiás UniEVANGÉLICA.

Foi utilizado facão para a coleta, as amostras foram acondicionadas em folhas de jornal, ao abrigo da luz, para que a secagem pudesse acontecer naturalmente.

\subsection{Obtenção dos extratos de $L$. ferrea}

A obtenção dos extratos de L. ferrea foi realizada de acordo com Moraes e colaboradores (2010) com modificações, por se tratar de espécies diferentes de plantas, mas igualitariamente quanto à marcha analítica. As amostras (secas em temperatura ambiente) de L. ferrea foram maceradas e, após esse processo, armazenadas em frasco escuro contendo etanol (proporção 1:4) mantido sob refrigeração. Posteriormente, esta amostra foi filtrada e seca com auxílio de rotaevaporador. O extrato resultante foi armazenado em um frasco âmbar ao abrigo da luz, a $4^{\circ} \mathrm{C}$ (Costa, 2013). 
As amostras das folhas de Libidibia ferrea foram pulverizadas em mixer, totalizando 30,42 g, e posteriormente colocadas em contato com $400 \mathrm{ml}$ de álcool 99\% para maceração por 24 horas.

Logo após o extrato etanólico foi filtrado, conforme se observa na figura 01, e colocado em um becker o qual foi envolvido com papel alumínio (ao abrigo da luz) e colocado na geladeira $\left(4^{\circ} \mathrm{C}\right)$. No período que antecedeu os experimentos, o extrato obtido foi colocado em um balão do tipo pera de $100 \mathrm{ml}$ e encaixado no rotaevaporador e vedado com um parafilme, em seguida foi imerso em água com uma temperatura de 45 graus Celsius e com uma rotação de 64 rotações por minuto que após 1 hora foi mudado para 80 rotações por minuto, para que todo o álcool fosse retirado. No primeiro dia o procedimento de rotaevaporação começou as 10:20 e terminou as 16:30, já no dia seguinte ficou das 8:00 ás 10:00 e assim foi obtido o extrato da planta com todo o álcool evaporado após 8 horas totais de secagem, como visto nas figuras 2 e 3.

Figura 1. Processo de filtração do extrato etanólico de L. ferrea com álcool a 99\%. Foi despejado sobre um filtro de papel, acoplado a um funil de vidro.

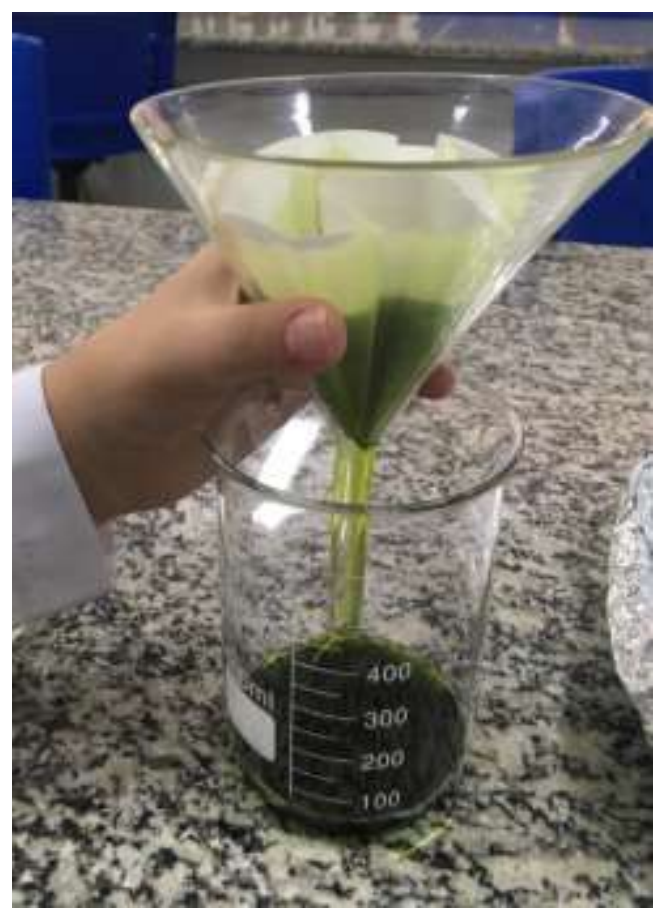

Fonte: Autores. 
Figura 2. Secagem do extrato obtido, sendo colocado em balão do tipo pera de $100 \mathrm{ml}$. Em seguida, encaixou-o em um rotaevaporador vedado com um parafilme. Posteriormente, foi imerso em água com uma temperatura de 45 graus Celsius.

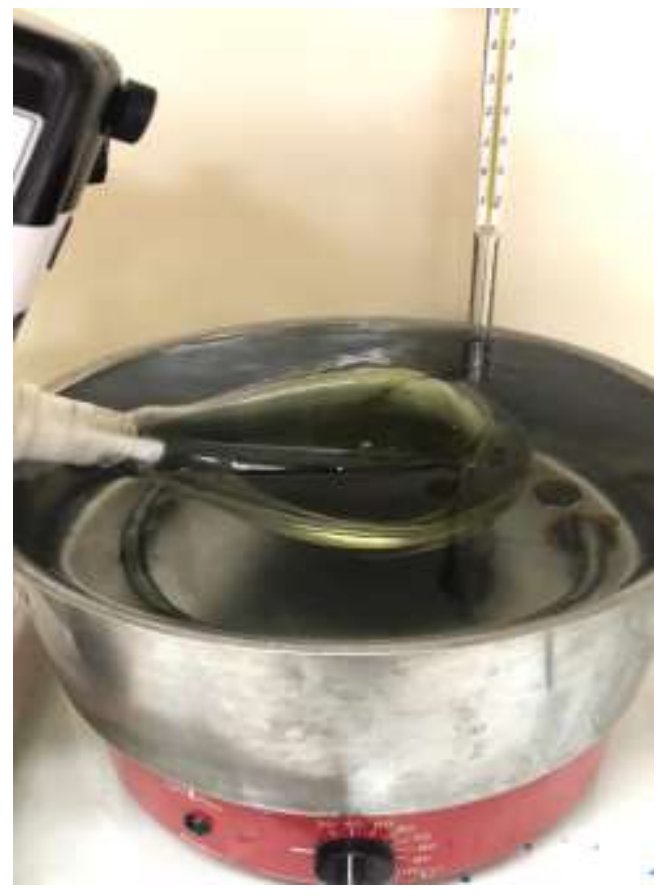

Fonte: Autores.

Figura 3. Processo de rotaevaporação o qual ocorreu para que retirasse todo o álcool restante do extrato. Nesta dinâmica, a secagem total do álcool no extrato de L. ferrea ocorreu em oito horas.

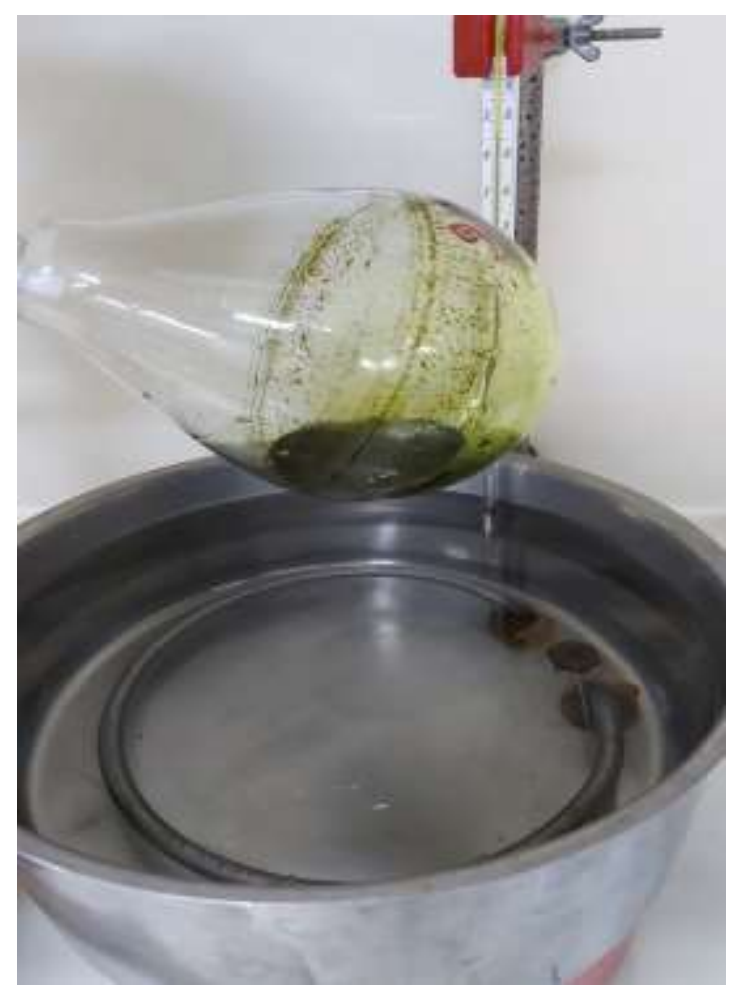

Fonte: Autores. 


\subsection{Cultivo e manutenção do fungo}

Para a realização do cultivo, as cepas de C. albicans, C. parapsilosis, C. tropicalis ATCC (American Type Culture Collection 2019) foram cultivadas em meio Ágar Sabouraud Dextrose (Peptona 10g/L; Dextrose 40g/L; Ágar 15g/L). As cepas foram mantidas em estufa a $36^{\circ} \mathrm{C}$ por 72 horas, quando foram submetidas à experimentação ou novo repique (Menezes et al., 2012).

\subsection{Teste de sensibilidade em placas}

Para o teste de sensibilidade em meio sólido, amostras contendo um número de $10^{4}$ células de C. albicans, C. parapsilosis, e C. tropicalis com três dias de crescimento em $30 \mathrm{~mL}$ de ágar nutriente suplementado com glicose, foram transferidas para novas placas que contenham o mesmo meio de cultura somado aos extratos de L. ferrea em diferentes concentrações. As placas foram incubadas por três dias a $36^{\circ} \mathrm{C}$ antes de serem fotografadas, de acordo com Betoni et al. (2006) com modificações, por se tratar de espécies diferentes de microrganismos, seguindo-se os preceitos metodológicos, com exceção do tempo de cultivo antes da fotografia ( 3 dias ao invés de 24 horas).

\subsection{Teste de sinergismo}

Para o teste de sinergismo, foram preparadas placas-controle contendo os extratos de L. ferrea, além de placascontrole com drogas conhecidas (Fluconazol $30 \mathrm{mg} / \mathrm{mL}$ ). As placas de teste, para avaliação da atividade sinérgica entre extratos etanólicos de rizoma e folha de L. ferrea em combinação com fluconazol, foram construídas em triplicatas biológicas, sendo utilizadas as mesmas concentrações dos extratos da planta, bem como de fluconazol das placas-controle. As placas foram incubadas por três dias a $36^{\circ} \mathrm{C}$ antes de serem fotografadas, segundo Betoni et al. (2006) com modificações, por se tratar de espécies diferentes de microrganismos, seguindo a mesma marcha analítica, com exceção do tempo de cultivo antes da fotografia ( 3 dias ao invés de 24 horas).

\subsection{Teste de sensibilidade por disco de difusão}

Discos de papel esterilizados (diâmetro de $6 \mathrm{~mm}$ ) foram embebidos previamente no extrato obtido da planta em diferentes concentrações. Posteriormente, foram inoculados $1,5 \times 10^{8}$ células $/ \mathrm{mL}$ de C. albicans, C. parapsilosis, e C. tropicalis em placas de meio nutriente e, em seguida, os discos serão retirados dos tubos com uma pinça esterilizada e colocados sobre as placas contendo o meio. As placas foram incubadas em estufa, a $36^{\circ} \mathrm{C}$ por três dias e, após esse período serão mensurados os halos de inibição do crescimento, em milímetros, com o auxílio de um paquímetro (Bauer et al., 1966, NCCLS, 2002).

\section{Resultados}

\subsection{Rendimento do extrato}

Depois do período de secagem as folhas de L. ferrea foram pulverizadas e em seguida feita a pesagem e o cálculo do rendimento (Quadro 1).

Quadro 1. Obtenção de extrato de L. ferrea.

\begin{tabular}{|c|c|c|c|c|}
\hline Espécie & Extrato & Massa $(g)$ & EE $(g)$ & Rendimento \\
\hline Libidibia ferrea & Folha & $30,42 g$ & 17,45 & $5,3 \%$ \\
\hline
\end{tabular}

EE: Extrato etanólico. Fonte: Autores.

Desse modo para 30,42 $\mathrm{g}$ de folhas, o percentual de rendimento de extrato foi de 5,3\%. 


\subsection{Teste de Sensibilidade de Placas}

Amostras contendo $10^{4}$ como concentração de células fúngicas foram inoculadas em meio ágar nutriente suplementados com o extrato de L. ferrea nas concentrações $0,250 \mathrm{mg} / \mathrm{ml}$ (T1), 0,50 mg/ml (T2) e 1,00 mg/ml (T3) e essas concentrações foram escolhidas de acordo com o estudo de Luna et al (2020).

Levando-se em consideração a placa controle, os resultados mostram que o crescimento de $C$. albicans (Figura 4) e $C$. tropicalis (Figura 5) foi inibido de maneira significativa na maior concentração testada (1,00 mg/ml) do extrato etanólico de $L$. ferrea.

Para C. parapsilosis (Figura 6) a inibição do fungo se dá, conforme observado, de maneira dose dependente a partir da segunda concentração testada, $0,50 \mathrm{mg} / \mathrm{ml}$ do extrato etanólico de $L$. ferrea, sugerindo uma maior fragilidade de C. parapsilosis sob os efeitos do extrato.

Figura 4. Crescimento de C. albicans em ágar nutriente suplementado com extrato etanólico de Libidibia ferrea nas concentrações $0,250 \mathrm{mg} / \mathrm{ml}$ (T1), 0,50 mg/ml (T2) e 1,00 mg/ml (T3), comparado com a placa controle contendo C. albicans sem extrato.

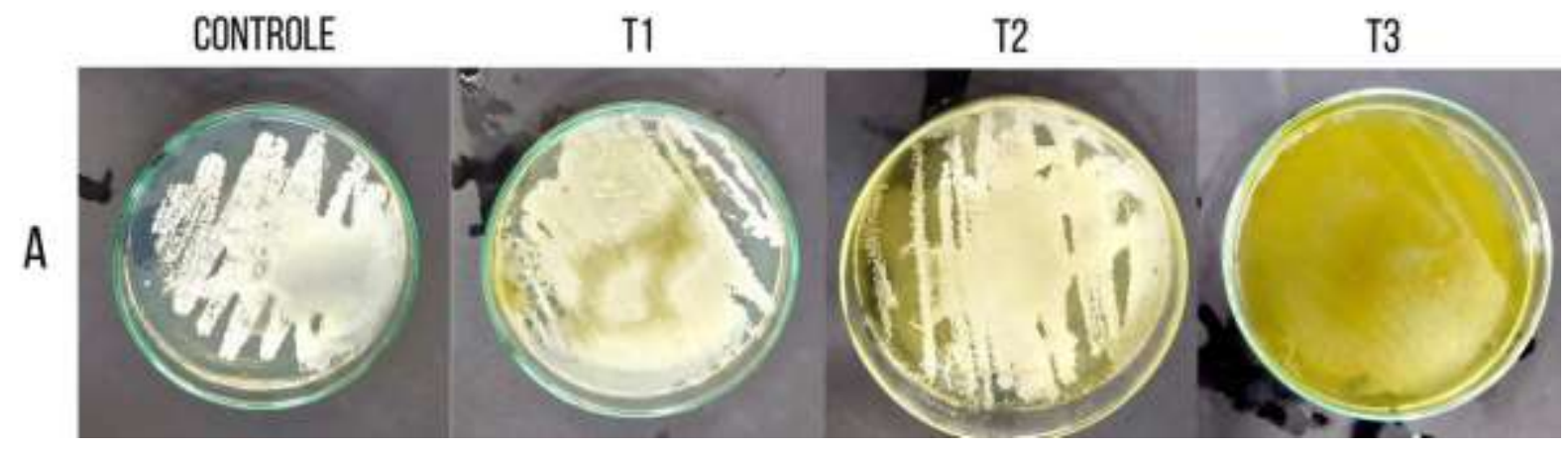

Fonte: Autores.

Figura 5. Crescimento de C. tropicalis em ágar nutriente suplementado com extrato etanólico de Libidibia ferrea nas concentrações $0,250 \mathrm{mg} / \mathrm{ml}$ (T1), 0,50 mg/ml (T2) e 1,00 mg/ml (T3), comparado com a placa controle contendo C. tropicalis sem extrato.

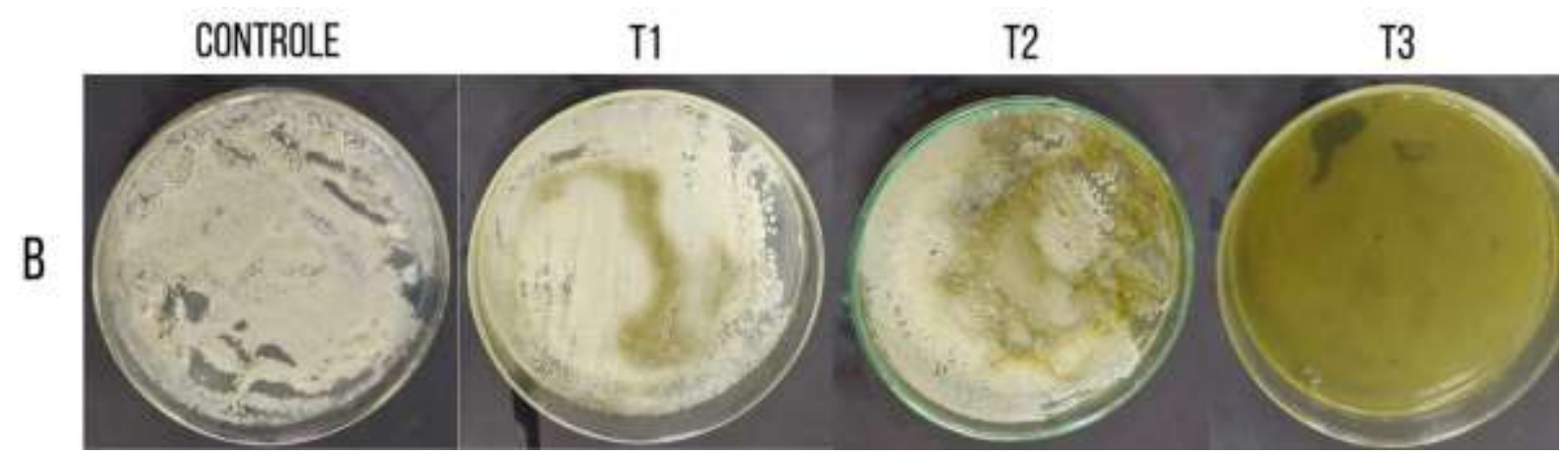

Fonte: Autores. 
Figura 6. Crescimento de C. parapsilosis em ágar nutriente suplementado com extrato etanólico de L. ferrea nas concentrações $0,250 \mathrm{mg} / \mathrm{ml}$ (T1), $0,50 \mathrm{mg} / \mathrm{ml}$ (T2) e $1,00 \mathrm{mg} / \mathrm{ml}$ (T3), comparado com a placa controle contendo $C$. parapsilosis sem extrato.

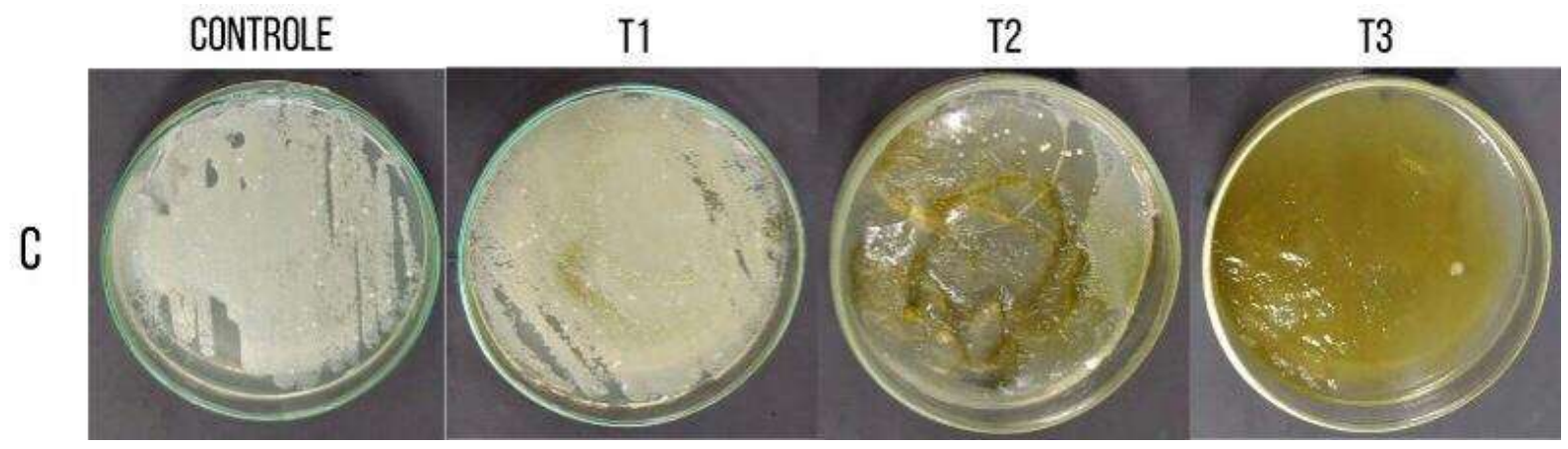

Fonte: Autores.

\subsection{Teste de sensibilidade por disco de difusão}

O teste de sensibilidade por disco de difusão foi realizado para avaliar a sensibilidade antifúngica do extrato de $L$. ferrea sobre $C$. albicans, $C$. parapsilosis, e $C$. tropicalis. O experimento foi realizado através de duas placas contendo meio de cultura Agar nutriente, onde posteriormente foi inoculado células de C. albicans, C. parapsilosis, e C. tropicalis e adicionado discos de papel filtro embebidos no extrato da folha em diferentes concentrações, sendo elas: $250 \mathrm{mg} / \mathrm{ml}$ (T1), 0,50 mg/ml (T2) e 1,00 mg/ml (T3). As placas foram mantidas à temperatura ambiente, e no terceiro dia foi realizado o memorial fotográfico. Levando em consideração os halos de inibição, os resultados mostram que das concentrações utilizadas do extrato de $L$. ferrea, não foi possível observar a inibição do crescimento de C. albicans (Figura 7) e C. tropicalis (Figura 8) e C. parapsilosis (Figura 9), em nenhuma das concentrações realizadas.

Figura 7. Placa contendo cultura ágar nutriente com discos de difusão embebidos no extrato etanólico de $L$. ferrea. Nesta placa, foi possível observar o crescimento de C. albicans e a ausência de halos de inibição.

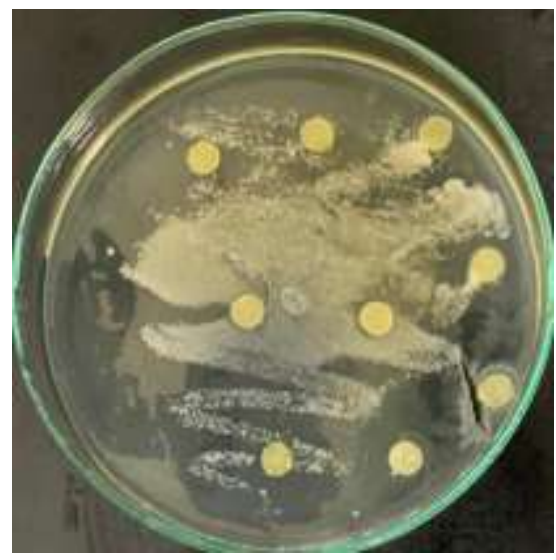

Fonte: Autores. 
Figura 8. Placa contendo cultura ágar nutriente com discos de difusão embebidos no extrato etanólico de L. ferrea. Nesta placa, foi possível observar o crescimento de $C$. tropicalis e a ausência de halos de inibição

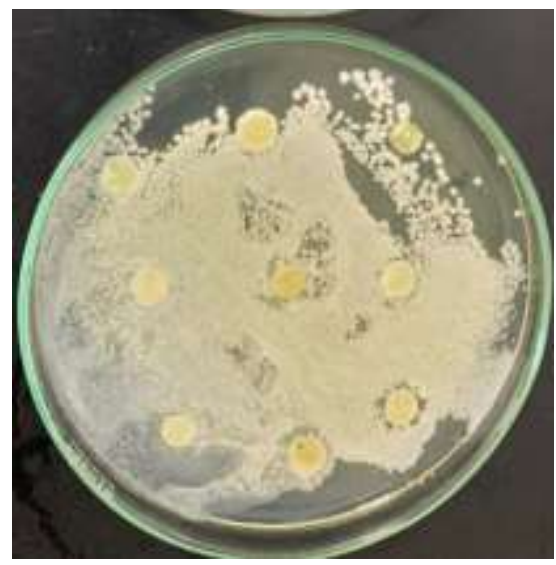

Fonte: Autores.

Figura 9. Placa contendo cultura ágar nutriente com discos de difusão embebidos no extrato etanólico de $L$. ferrea. Nesta placa, foi possível observar o crescimento de C. parapsilosis e a ausência de halos de inibição.

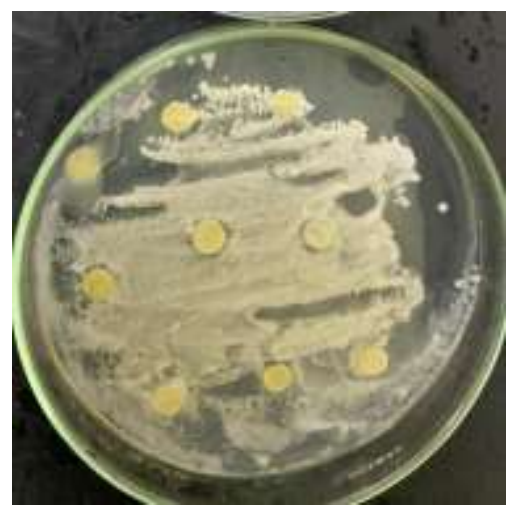

Fonte: Autores.

\subsection{Teste de Sinergismo}

O teste de sinergismo foi realizado para avaliar possível interação entre o extrato de L. ferrea e antifúngicos convencionais, como o fluconazol. Foram cultivadas placas de teste, para avaliação da atividade entre o extrato em combinação com fluconazol $30 \mathrm{mg} / \mathrm{ml}$, construídas em triplicatas biológicas, utilizando as mesmas concentrações dos extratos da planta, bem como de fluconazol das placas-controle. As placas foram incubadas por três dias a $36^{\circ} \mathrm{C}$ antes de serem fotografadas.

Quando comparados com a placa-controle sem nenhum inibidor (Figura 10), os resultados mostram presença de atividade sinérgica na placa que contém extrato de $L$. ferrea e fluconazol no que se remete a inibição da proliferação de $C$. parapsilosis, sendo tal efeito visível nas concentrações T2 e T3, com respectivos 0,50 mg/ml (T2) e 1,00 mg/ml (T3) de extrato, junto a $30 \mathrm{mg} / \mathrm{ml}$ de fluconazol.

Já nas demais espécies, $C$. Albicans e $C$. tropicalis, não se observou atividade sinérgica ou antagônica pela interação extrato e fluconazol. 
Figura 10. (A) representação de $C$. Albicans placa controle, controle com fluconazol, e interação entre o extrato de Libidibia e fluconazol nas concentrações, $0,250 \mathrm{mg} / \mathrm{ml}$ (T1), 0,50 mg/ml (T2) e 1,00 mg/ml (T3). (B) representação de C. tropicalis placa controle, controle com fluconazol, e interação entre o extrato de Libidibia e fluconazol nas concentrações0,250 mg/ml (T1), $0,50 \mathrm{mg} / \mathrm{ml}$ (T2) e 1,00 mg/ml (T3). (C) representação de C. Parapsilosis placa controle, controle com fluconazol, e interação entre o extrato de Libidibia e fluconazol nas concentrações, $0,250 \mathrm{mg} / \mathrm{ml}$ (T1), 0,50 mg/ml (T2) e 1,00 mg/ml (T3).

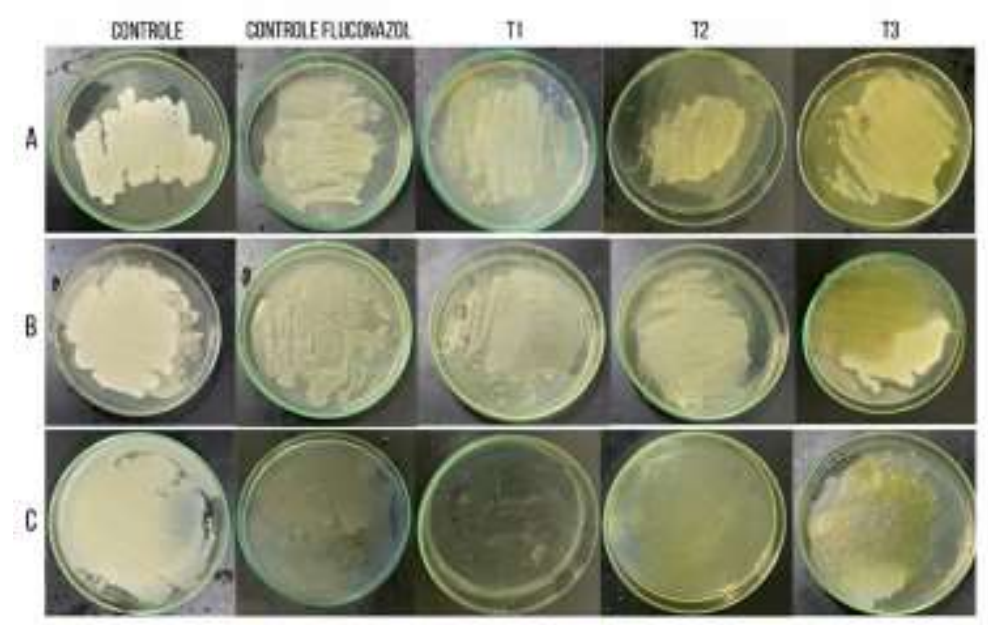

Fonte: Autores.

\section{Discussão}

\section{Rendimento do extrato}

Paiva et al (2015), em seu trabalho, utilizou 300g da planta para um litro de álcool etílico absoluto, que, após todo processo de extração do material, obteve-se uma solução de 14,8g, tendo como rendimento de extrato 4,9\%. Essa diferença do rendimento do extrato pode ser explicada devido ao local de coleta da amostra, a idade da planta e ao tempo de exposição ao álcool utilizada no extrato de Paiva et al (2015).

\section{Teste de sensibilidade de placas}

Como também demonstrado pelo trabalho de Paiva (2015), o extrato etanólico da L. ferrea teve inibição satisfatória em células fúngicas, assim como em bactérias, como Staphylococcus aureus e Eschorichia coli. A aplicação do extrato bruto resultou em uma inibição de 61\%, sendo que a aplicação do extrato com concentração de 70\%, resultou em uma inibição de $27 \%$ e com o extrato com concentração de $50 \%$ ocorreu uma inibição menor de cerca de $5 \%$, presentes no leite de cabra, causadores de mastite. Além disso, o trabalho de Oliveira et al. (2013) também obteve resultados positivos com o uso do extrato etanólico da L. ferrea em microrganismos comuns da microbiota bocal, como Streptococcus oralis, Strptococcus salivarius, Lactobacillus casei, Candida albicanse Streptococcus mutans. Por fim, pode-se observar inibição bacteriana no trabalho de Tomaz (2013), conseguindo resposta contra cepas de Streptococcus aureus e Eschorichia coli.

\section{Teste de sensibilidade por disco de difusão}

No trabalho de Sousa e colaboradores (2018) foi testado o extrato aquoso de folhas e caules de Costusspiralis (Jacq.) para avaliação da capacidade antifúngica contra cepas de Candida. As concentrações de extrato de $C$. spiralis usadas não demostraram atividade inibitória contra $C$. albicans ou $C$. parapsilosis. Resultado semelhante foi encontrado no estudo aqui conduzido em relação a C. albicans e C. parapsilosis. Já no trabalho de Akpan e colaboradores (2012) utilizando o método de disco de difusão, o extrato etanólico de Costusafer nas concentrações de $150 \mathrm{mg} / \mathrm{mL}, 100 \mathrm{mg} / \mathrm{mL}$ e $50 \mathrm{mg} / \mathrm{mL} \mathrm{mostrou}$ 
eficácia contra $S$. aureus, S. pneumoniae e E. coli, enquanto P. aeruginosa e $S$. pyogenes foram suscetíveis em alta concentração $150 \mathrm{mg} / \mathrm{mL}$ e $100 \mathrm{mg} / \mathrm{mL}$.

Enquanto no trabalho de Moreira e colaboradores (2021) a C. albicans se mostrou susceptível aos extratos brutos dos vegetais Apis melífera L. com média dos halos de suscetibilidade de 18mm e Caryocar brasiliense, com média dos halos de suscetibilidade de e $26 \mathrm{~mm}$ e, contudo, apresentou resistência a ação dos extratos de Morinda citrifolia L., Morusalba L e Annona muricata L., também testados pelo estudo.

\section{Teste de Sinergismo}

Vários estudos descrevem o sinergismo entre compostos oriundos de plantas e antifúngicos tradicionalmente utilizados. Ação sinérgica entre extratos de Eiseniabi cyclis $(4 \mathrm{mg} / \mathrm{mL})$ e fluconazol foi encontrada por Kim e colaboradores (2014), bem como também foi observado por Rukayadi e colaboradores (2009) entre o sesquiterpenoxantorizol obtido de Curcuma xanthorrhiza (Gengibre javanês) e anfotericina B sobre Candida spp.

Ademais, a associação entre os extratos de plantas e antimicrobianos tradicionalmente utilizados também pode gerar antagonismo. Tal situação foi vista por Castro (2010) com a associação entre o óleo essencial de Cinnamomum zeylanicum (Caneleira) e o antifúngico miconazol diante das cepas de C. albicans. Na pesquisa de Tintino e colaboradores (2013), extratos etanólicos de Costusarabicu (Canela-de-ema) apresentaram antagonismo quando associados ao antifúngico nistatina sobre Candida krusei.

\section{Considerações Finais}

No que tange a sensibilidade da L. ferrea contra as células de C. albicans, C. parapsilosis e C. tropicalis, o crescimento de $C$. albicans e $C$. tropicalis foi inibido de maneira significativa na maior concentração testada (1,0 mg/ml) do extrato etanólico de L. ferrea. Para C. parapsilosis a inibição do fungo se dá, também de maneira dose dependente, porém a partir da segunda concentração testada, $0,50 \mathrm{mg} / \mathrm{ml}$ do extrato etanólico de L. ferrea.

Assim, pode-se concluir que o extrato etanólico de L. ferrea apresenta atividade antifúngica sobre C. albicans, C. parapsilosis e $C$. tropicalis de maneira dose dependente, evidenciando o potencial antifúngico da planta utilizada no estudo.

\section{Referências}

Akpan, M. M. (2012). Antimicrobial Assessment Of Ethanolic Extract Of Costusafer Leaves. Asian Journal Of Plant Science And Research, 2 (3),335-341. $10.1590 / 1089-6891 v 20 \mathrm{e}-57228$.

Bauer, A.W, Kirby, W. M. M., Sherris, J.C. \&Turck, M (1966). Antibiotic Susceptibility. Testingby A Standartized Single Disc Method. Am J Clinpathol, 45(4), 493-496. Disponível em: Https://Doi.Org/10.1093/Ajcp/45.4_Ts.493

Betoni, J.E.C (2006). Synergism Between Plant Extract And Antimicrobial Drugs Used On 33 Staphylococcus Aureus Diseases. Memorias Do Instituto Oswaldo Cruz, 101, (4), 387- 34 390.Https://Doi.Org/10.1590/S0074-02762006000400007.

Campo, T. M. \& Cosentino, C. M.R (2019). Avaliação Do Comportamento De Leveduras Do Gênero Cândida A Fármacos Antifúngicos. Revista De Trabalhos Acadêmicos Da FAM, 4 (1), 17-24.

Castro, R. D (2010). Atividade Antifúngica In Vitro Do Óleo Essencial De Eucalyptus Globulus L. Sobre Candida Spp. Revista Odontológica Da Unesp, 39 (3), 179-184.

Cavalheiro, M. G. (2009). Atividades Biológicas E Enzimáticas Do Extrato Aquoso De Sementes De Caesalpiniaferreamart,Leguminosae. Revista Brasileira De Farmacognosia,19 (2), 586-591 Https://Doi.Org/10.1590/S0102-695x2009000400014.

Colombo, A. L \& Guimarães, T. (2003). Epidemiologia Das Infecções Hematogênicas Por Candida Spp. Revista Da Sociedade Brasileira De Medicina Tropical, 36 (5), 599-60.Https://Doi.Org/10.1590/S0037-86822003000500010.

Costa Fib (2013). Caracterização E Avaliação Da Atividade Antioxidante De Farinhas Produzidas A Partir Dos Resíduos De Umbu (Spondias Tuberosa Arruda Cam.) E Maracujá Do Mato (Passifloracincinnatamast.). Itapetinga. Programa De Pós-Graduação Em Ciências Ambientais - Universidade Estadual Do Sudoeste Da Bahia. 
Research, Society and Development, v. 10, n. 16, e285101623645, 2021

(CC BY 4.0) | ISSN 2525-3409 | DOI: http://dx.doi.org/10.33448/rsd-v10i16.23645

Gazim, Z. C. (2007). Antifungal Activity Of The Essential Oil From Calendula Officinalis L. (ASTERACEAE) Growing In Brazil. Brazilian Journal Of Microbiology, 39(1), 61-63. Https://Doi.Org/10.1590/S1517-83822008000100015.

Golan, E. J. A. E. L. B (2014). Princípios De Inflamação E O Sistema Imune. In: Princípios Da Farmacologia. $8^{a}$. Ed. Rio De Janeiro: Guanabara Koogan LTDA.

Kim, K., Eom, S. H, Kim, H., Nshimiyumukiza, O., Kim, D. \& Lee, M. (2014). Antifungal and Synergistic Effects of an Ethyl Acetate Extract of the Edible Brown Seaweed Eiseniabicyclis against Candida Species. FisheriesandAquaticSciences, 17, 209-214. https://doi.org/10.5657/FAS.2014.0209.

Lopes, A. C. (2018). Tratado de Clínica Médica. Guanabara Koogan LTDA

Luna, M. S. M. (2020). Bioprospecção de metabólitos secundários de Libidibia ferrea var. ferrea. South African Journal of Botany, 130, 103-108. https://bdtd.ibict.br/vufind/Record/UFPE_ddd6313cac97d3cf03207e45567a8c94.

Menezes, E. A., Junior, A. A. V., Cunha, F. A., Braz, B. H. L. \& Silva, C. L. F. (2012). Identificação Molecular suscetibilidade antifúngica de Candida parapsilosis isoladas no Ceará, Brasil. J BrasPatolMedLab, 48, 415-420. https://doi.org/10.1590/S1676-24442012000600005.

Moraes, J. Q., Nunes, J. R. S., Pinheiro, A. P. \& Pessoa, S. P. M. (2010).Etnobotânica de plantas medicinais com alunos do ensino médio de um colégio estadual de Tangará da Serra-MT.3 $3^{a}$ jornada científica da Unemat, Cáceres/MT Brasil. https://doi.org/10.34117/bjdv6n5-229

Pereira, L. V. de A. C., Silva, L. C., Sá, M. C. de, Moreira, M. de C., Nascimento, G. L. M. S. do, Andrade, T. C. de, Santos, V. M. dos, \& Silva, F. L. da. (2021). In vitro analysisoftheantifungicalactivityofplantextractsagainstyeastsbelongimgtotheCandidaalbicansspecies. Research, Society andDevelopment, 10(10), e440101019075. https://doi.org/10.33448/rsd-v10i10.19075

Pereira, M. S. V., Rodrigues, O. G., Feijó, F. M. C., et al. (2016). Atividade antimicrobiana de extratos de plantas no Semiárido Paraibano. Agropecuária Científica no Semiárido, 2(1), 37-43. http://dx.doi.org/10.30969/acsa.v2i1.19

Prado, R. S., Alves, R. J., Oliveira, C. M. A., Kato, L., Silva, R. A., Quintino, G. O., Cunha, S. D., Soares, C. M. A. \& Pereira, M. (2014). Inhibition of Paracoccidioides lutzii $\mathrm{Pb} 01$ Isocitrate Lyase by the Natural Compound Argentilactone and Its Semi-Synthetic Derivate. Plosone, 9 (4), 11-13. https://doi.org/10.1371/journal.pone.0094832

Rukayadi, Y., Lee, K., Lee, M., Yong, D. \& Hwang, J. (2009). Synergistic Anticandidal Activity of Xanthorrhizol in Combination with Ketoconazole or Amphotericin B. FEMS Yeast Research, 9, 1302-1311. https://doi.org/10.1111/j.1567-1364.2009.00548.x

Silva, C. W. V., Pinheiro, E., O., P., Moreira, M., L., M., Teixeira, RC., G., \& Oliveira, CP., A. (2018). Candidíase vulvovaginal e patogenicidade dos fungos infectantes. Mostra Científica da Farmácia, 5. http://publicacoesacademicas.unicatolicaquixada.edu.br/index.php/mostracientificafarmacia/article/view/2958

Sousa, Wendel C. et al. (2018). In vivo assessment of cyto/genotoxic, antigenotoxic and antifungal potential of Costusspiralis (Jacq.) Roscoeleavesandstems. An. Acad. Bras. Ciênc.,90 (2), 1565-157. 10.1590/0001-3765201720170714

Tintino, S. R., et al. (2013). Avaliação In vitro da atividade antimicrobiana e moduladora dos extratos etanólico e hexânico de bulbo de Costusarabicus. BioscienceJournal, 29(3), 732-738. http://www.seer.ufu.br/index.html

Tomaz, A. M., et al. (2013). Sensibilidade de isolados de Candida spp. a antifúngicos por disco-difusão em ágar e microdiluição em caldo. BioscienceJournal,30(1),304-310. http://www.seer.ufu.br/index.html.

Veronesi-Focaccia. (2015). Tratado de Infectologia. Atheneu. 